\title{
Reviewing the Influence of Welding Setup on FE-Simulated Welding Residual Stresses
}

\author{
Stefanos Gkatzogiannis ${ }^{1, a,{ }^{*}}$, Peter Knoedel ${ }^{1, b}$ and Thomas Ummenhofer ${ }^{1, \mathrm{c}}$ \\ ${ }^{1}$ KIT Steel \& Lightweight Structures, Research Center for Steel, Timber \& Masonry, Otto- \\ Ammann-Platz 1, D-76131 Karlsruhe, Germany \\ a stefanos.gkatzogiannis@kit.edu, ${ }^{b}$ peter.knoedel@kit.edu, ${ }^{c}$ thomas.ummenhofer@kit.edu
}

Keywords: Welding Residual Stresses, FE Simulation, Boundary Conditions, Heat Input, Material Model, Aluminum, Steel

\begin{abstract}
Previous and new simulations of welding residual stresses with the finite element method are reviewed in the present study. The influence of modelling mechanical boundary conditions, erroneous prediction of the weld heat source coefficient and the influence of microstructural changes in aluminum welds are investigated. The results are analyzed so that concrete suggestions regarding the investigated factors, acting as guidance to the practitioner, can be presented.
\end{abstract}

\section{Introduction}

Finite element (FE) simulation of welding has evolved rapidly in the last decades, although the major goal has ever since remained the same, i.e. the calculation of welding residual stresses (WRS) and plastic strains. The possibility to take into consideration even more effects of real welding in the simulation increased therewith as well. Nevertheless, welding is a complex multiphysics process and many different phenomena (electromagnetic, thermal, mechanical etc.) take place, as it was thoroughly described by Francis et al. [1]. A new challenge has therefore arisen for modern engineers: take into consideration only those factors who exhibit a nonnegligible influence on welding residual stresses, depending on the desired preciseness level of each investigated case, in order to balance computational cost and enable better overview of the modelling approach by the practitioner. Straightforward modelling approaches can provide precise results, as long a proper choice of the factors to be taken into consideration is made [2].

Lindgren proposed a concept of filtering simulated factors based on the desired precision [3], from down to basic up to very accurate levels of simulation, by making, nevertheless, a qualitative and not quantitative evaluation. The influence of each simulated factor on the welding residual stresses can differ in each investigated case. For example, the influence of clamped edges, which is proven to have a significant effect on the transverse WRS [4] of butt-welds, is expected to be less significant in the case of fillet welds. Therefore, an investigation of the influence of individual factors on WRS is necessary for a further improvement of welding simulation techniques.

The present study reviews previous and new FE simulations in order to evaluate the influence of selected factors of welding simulation. A review of selected welding parameters and modelling approaches, regarding their influence on WRS, is carried out, with the objective to offer guidance to the practitioner.

\section{Theoretical Background}

As already previously discussed, welding is a multiphysics problem, but simulation of WRS requires modelling only of some aspects of the welding process. The thermal behavior and possible microstructural changes are investigated along with the mechanical behavior of a 
component when WRS are under the scope. These three fields, which are presented in Fig. 1 are interacting bidirectionally with each other. Practical models, predicting the WRS with satisfying preciseness by only simulating the interaction of thermal on microstructural and mechanical behavior and of microstructural field on the mechanical behavior have been developed [2]. The considered interactions are presented in Fig. 1. Ignoring the reverse influence of microstructural and mechanical behavior enables solution of the problem with a sequential unidirectionally coupled thermal-mechanical analysis [2]. A description of the numerical background is avoided in the present case for sake of space, but it is thoroughly provided in previous work of the authors [2].

Modelling of the thermal field includes the simulation of the weld heat source, the heat transfer inside the investigated component and heat losses to the surrounding environment (boundary conditions). The Goldak's double ellipsoidal is the state-of-the-art approach for modelling the weld heat source [5]. The effective heat input is predicted by multiplying the power of the heat source with a coefficient of the weld heat source. Proposed values of this coefficient for various weld types are proposed in [6]. Nevertheless, different values usually in a range of $\pm 10 \%$ for same welding types are found elsewhere (see [7] etc.). Heat transfer inside the component is governed by three dimensional Fourier's law of heat conduction. Heat losses are modelled according to Newton's law of cooling. A transient thermal analysis is carried out, whereby the temperature history of the nodes of the FE model are saved at each solution step.

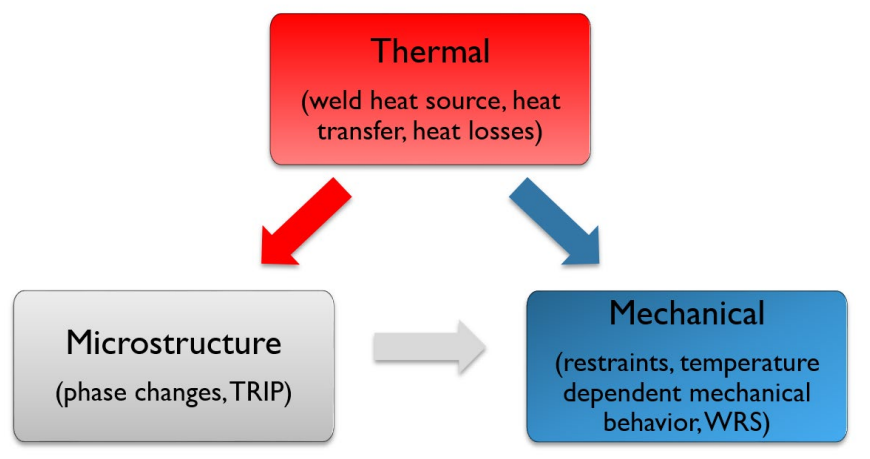

Fig. 1: Investigated fields and respective interactions in an engineering approach for arc welding simulation, TRIP stands for transformed induced plasticity [2]

Regarding the modelling of the microstructural changes that take place, different models have been proposed in the past. A straightforward engineering approach, which was proposed by the authors of the present study [2], provided results with sufficient preciseness and can be applied for the simulation of various materials [8], [9], [10]. Main feature of the approach lies on the assignment of material models to the finite elements inside the fusion zone (FZ) and the heataffected zone (HAZ) during cooling down based on predominant parameters of the thermal cycle, in order to simulate the modified mechanical behavior of the transformed microstructure. The selection of material models is based on predictions of the transformed microstructure according to continuous cooling transformation (CCT) diagram or assessment of microstructure through measurements. The importance or negligibility of microstructural changes during modelling of ferritic or austenitic steels respectively has been confirmed in the past [2], [9]. Softening in the HAZ of aluminum alloys was as well successfully modelled elsewhere [8]. Nevertheless, a quantification of this influence on WRS is not known to the authors of the present study. The same problem arises as well when high strength steels are regarded. Liu et al. [11] and Lee and Chang [12] simulated weldments by ASTM A514 (yield strength of $717 \mathrm{MPa}$ ) with phase changes and a high strength carbon steel with yield strength of $790 \mathrm{MPa}$ by neglecting them respectively. 
Finally, during modelling of the mechanical field, the nodal temperature history from the transient thermal analysis is applied as external thermal strains. Solution takes place in a static structural analysis, whereby temperature dependent material parameters and the restraints applied to the real welded component are modelled [10]. Usually, components are clamped down during welding. Fixing of the respective nodes in the FE models is a common approach of modelling but deviates from physical restraining reality. An alternative approach applied elsewhere [10] is the use of linear spring elements, restraining the respective nodes (see Fig. 4). Further steps of the mechanical solution are based on classical finite element theory for nonlinear materials.

\section{Investigated Factors}

Results from previous and new FE analyses, which were all carried out according to the abovedescribed theoretical background, are presented in the current study in order to review specific aspects of weld simulation. FE commercial software ANSYS [13] was applied in all cases. Solid 8 node elements "solid 90" and "solid 180" were applied for the transient thermal and the static structural analyses respectively in all cases. The following aspects are investigated:

- Modelling of mechanical boundary conditions (BC): A single-pass weld component of Swedish steel HT36 (equivalent to S355) with dimensions of $2000 \mathrm{~mm}$ x $1000 \mathrm{~mm}$ x $15 \mathrm{~mm}$ was simulated in [10] (component A in the present study). Geometry of the weld section is presented in Fig. 2. The component was welded with submerged-arc welding (three electrodes welding consecutively), an electric power of $98 \mathrm{~kW}$ and a welding speed of 25 $\mathrm{mm} / \mathrm{s}$ (150 cm/min; $3.92 \mathrm{~kJ} / \mathrm{mm}$ heat input). Applied material parameters are given in [2]. Clampers were modelled either by fixing the respective nodes in all directions or by applying linear spring elements with stiffness of $10^{6} \mathrm{~N} / \mathrm{mm}$ to all nodes in the clamped area in the longitudinal and transverse direction and fixing their vertical displacement. The results are compared with measurements for an identical component found elsewhere [7].

- Thermal input and welding sequence of multi-pass welds: Influence on the WRS, which can be caused by possible erroneous modelling of thermal heat input is investigated in [9]. The 5pass X-grooved butt-weld with dimensions $300 \mathrm{~mm}$ x $300 \mathrm{~mm}$ x $10 \mathrm{~mm}$ by AISI 316L, which is presented in Fig. 2, was simulated (component B in the present study) and different cases of differentiating heat input were modelled. The component was initially considered to be welded with an electric power of $4.3 \mathrm{~kW}$, a welding speed of $5 \mathrm{~mm} / \mathrm{s}(30 \mathrm{~cm} / \mathrm{min}$; 0.86 $\mathrm{kJ} / \mathrm{mm}$ heat input) and the welding sequence A-B-C-D-E. Applied material parameters are given in [9]. Effective heat input was changed by either increasing the welding speed, or reducing the heat input (see Table 1). The results are reviewed from a different scope in the present study in order to estimate the possible error of calculated WRS under the assumption that an under- or overestimation of $\pm 10 \%$ of the weld heat source's efficiency has taken place.

- Microstructural modelling: Numerical studies regarding welding of Aluminum alloy initially presented at [8], are repeated in the present study, by neglecting this time the phase transformations, in order to evaluate qualitatively and quantitatively the influence of recrystallization in the HAZ of aluminum alloys on the simulated WRS. A single-pass V grooved component of EN AW-6060 welded with an electric power of $3.1 \mathrm{~kW}$ and a welding speed of $10 \mathrm{~mm} / \mathrm{s}(60 \mathrm{~cm} / \mathrm{min} ; 0.31 \mathrm{~kJ} / \mathrm{mm}$ heat input) is modelled.

\section{Results and Discussion}

The calculated longitudinal WRS for the HT36 component A are presented in Fig. 4. "Meas." stands for measured WRS found in [7], while "Fixed" and "Springs" are referring to the respective applied modelling approach of BC. In both cases, tensile longitudinal stresses, higher than the nominal yield limit of the material at room temperature are met in the FZ and HAZ and 
compressive stresses in the areas away from the weld. In the case of modelling with spring elements, tensile stresses of even up to $700 \mathrm{MPa}$ are met (yield strength in the weld area is higher than the nominal $355 \mathrm{MPa}$ due to the phase changes taken place - increase of bainitic and martensitic phases), while for the fixed case the maximum tensile stress is not higher than 450 $\mathrm{MPa}$. Although both approaches produce similar results qualitatively, the agreement of the spring model with the measurements inside the weld section is clearly better. Similar improvement due to use of spring elements was observed as well in the case of calculated transverse WRS [10].
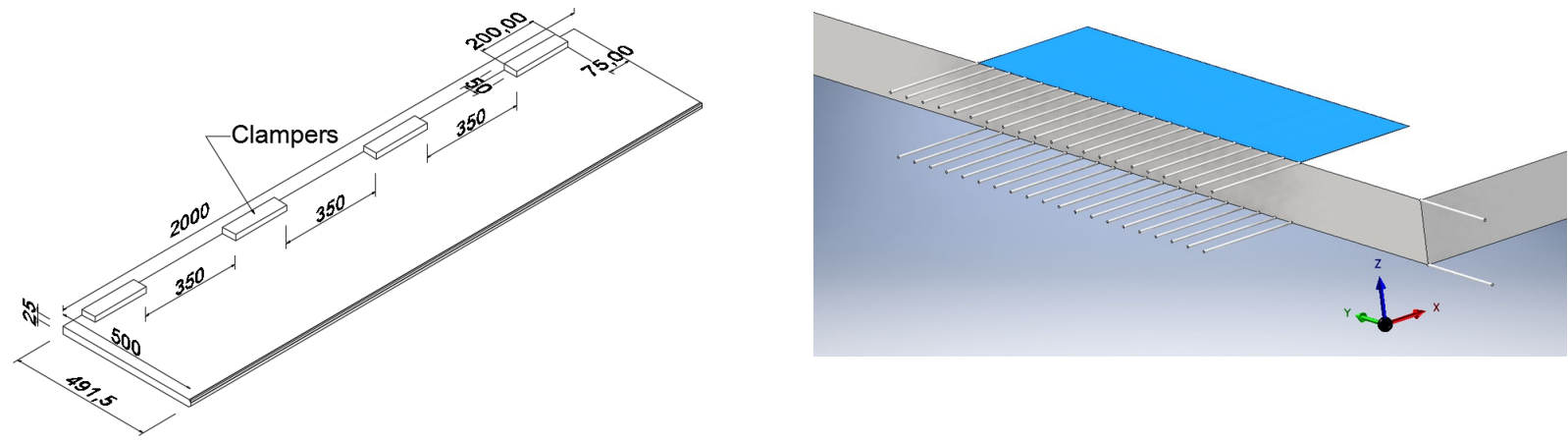

Fig. 2: Investigated component A - left: Geometry and clampers, dimensions are given in mm - right: Applied spring elements for the simulation of clampers

The calculated longitudinal WRS for the AISI 316L component B are presented in Fig. 4. Similar profiles of longitudinal WRS are calculated in all investigated cases (see Table 1). Tensile and compressive WRS are met near and away from the weld respectively. The increase of the heat input rate, either by increase of heat input or reduction of welding speed, shifts down the calculated profile of WRS. Nevertheless, the largest deviation from the initial profile (H1) is met in the case of reduced welding speed down to $50 \%$ (case V2). A difference of up to 150 $\mathrm{MPa}$ or $28 \%$ between the peak tensile stresses of those two cases is observed. Similar but not so significant differentiation of the transverse WRS profiles was observed as well [9].

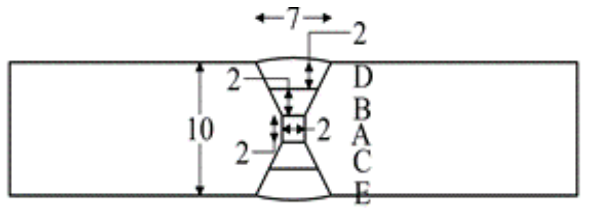

Fig. 3: Investigated component $B$, dimensions are given in $\mathrm{mm}$

\begin{tabular}{|c|c|c|}
\hline \multicolumn{2}{|c|}{ Table 1: Reviewed investigated cases found in [9] } \\
\hline $\begin{array}{c}\text { Investigated } \\
\text { case }\end{array}$ & Model & Investigated variable \\
\hline \multirow{4}{*}{$\begin{array}{c}\text { welding } \\
\text { parameters }\end{array}$} & $\mathrm{H} 1$ & initial welding parameters \\
\cline { 2 - 3 } & $\mathrm{V} 1$ & welding speed $-25 \%$ reduced \\
\cline { 2 - 3 } & $\mathrm{V} 2$ & welding speed $-50 \%$ reduced \\
\cline { 2 - 3 } & $\mathrm{Q} 1$ & heat input $-25 \%$ increased \\
\cline { 2 - 3 } & $\mathrm{Q} 2$ & heat input $-50 \%$ increased \\
\hline
\end{tabular}

The calculated WRS for the EN AW 6060 component C are presented in Fig. 5 for the cases of taking into consideration and neglecting the recrystallization in the HAZ. In the case of the longitudinal WRS the calculated profile differs significantly, both qualitatively and quantitatively, near the weld. Neglecting the microstructural changes, leads to a lower calculated peak stress and a shift of this peak stress from the boundaries between HAZ and parent material in the middle of the component. In the case of the transverse WRS, neglecting recrystallization causes a shift up of the calculated profile of up to $100 \mathrm{MPa}$.

\section{Conclusions}

The following conclusions were drawn, based on the above-presented results:

- Applied approach for modelling of clampers during a weld simulation can have a significant effect on the calculated WRS, at least in the case of butt-welds. The use of spring elements for modelling the longitudinal and transverse restraints in the clamped area produces results 
that show better agreement with experimentally measured WRS. Moreover, as higher tensile WRS are calculated, this approach lies on the safe side. This modelling approach is therefore suggested for adoption in practical applications as well.
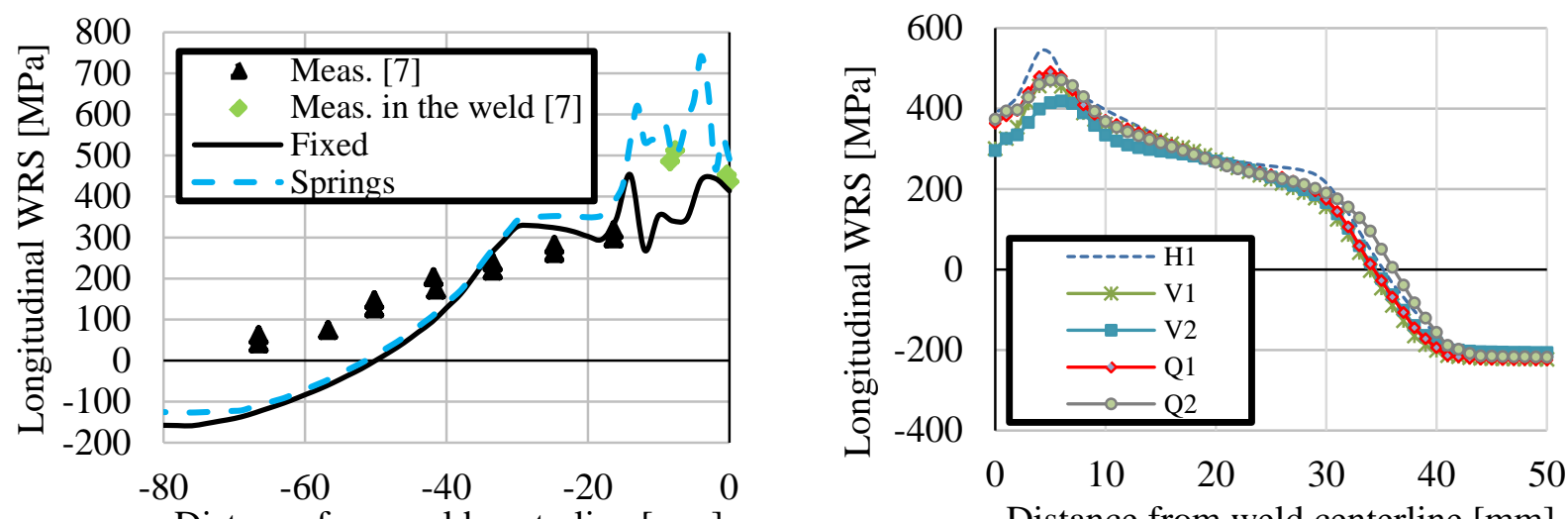

Distance from weld centerline [mm]

Distance from weld centerline [mm]

Fig. 4: Longitudinal WRS - left: Component A - right: Component B, resulting WRS on the top of the component, for the investigated cases presentes in Table 1

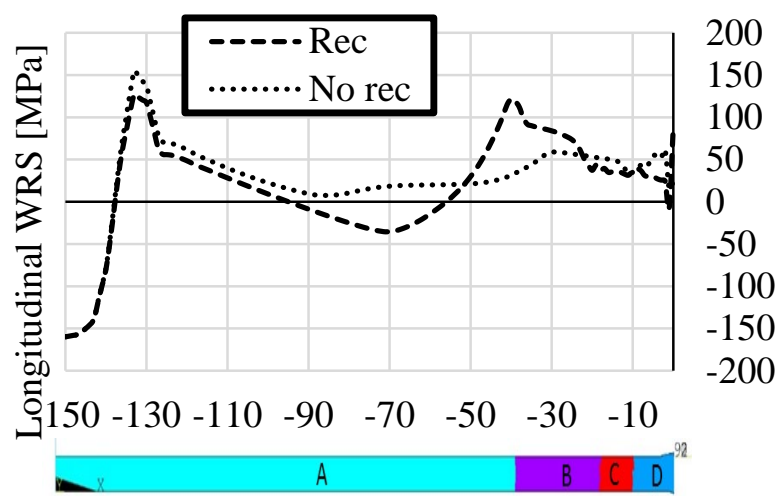

Distance from weld centerline [mm]

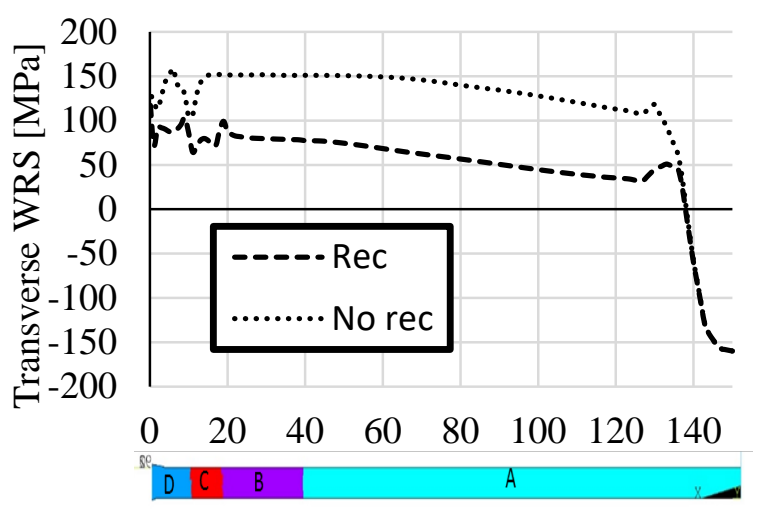

Distance from weld centerline [mm]

Fig. 5: WRS of the alluminum component $C$ with and without modelling of recrystilisation in the HAZ, collored areas of the component show modelling of the microstructural changes, A: parent material, B: HAZ $50 \%$ recrystalized, C: HAZ $100 \%$ recrystlized, D: FZ.

- A possible erroneous modelling of the weld heat source could lead to an underestimation of the WRS and therefore non-conservative results. An increase of $50 \%$ of the heat input rate led to a reduction of $28 \%$ of the peak tensile stress (worst case scenario). Assuming a linear behavior, an overestimation of $10 \%$ of the heat source coefficient would lead to an underestimation of $5.6 \%$ of the peak tensile stresses. This deviation lies in the boundaries of the acceptable numerical error, of practical weld simulations ( $\pm 10 \%$ [2]). Therefore, applying values for the coefficient of weld heat source from literature or previous measurements during the simulation of WRS, is considered valid.

- Aluminum welding simulations neglecting the recrystallization in the HAZ, produce erroneous results. A lower longitudinal peak stress is calculated and is present at the middle of the component. Simulations considering the microstructural changes show that the peak stress is met on the boundaries of the HAZ, exhibiting a much more crucial case, regarding fatigue strength of the investigated component. Therefore, neglecting recrystallization in the HAZ of aluminum weld during weld simulation is not conservative and should be avoided. 


\section{Acknowledgement}

The above-presented work was carried out as a part of the framework of a $\mathrm{PhD}$ thesis at Karlsruhe Institute of Technology [16].

\section{References}

[1] J.A. Francis, H.K.D.H. Bhadeshia, P.J. Withers, Welding residual stresses in ferritic power plant steels, Material Science and Technology 23 (2007) 1009-1020.

https://doi.org/10.1179/174328407X213116

[2] P. Knoedel, S. Gkatzogiannis, T. Ummenhofer, Practical aspects of welding residual stress simulation, Journal of Constructional Steel Research 132 (2017) 83-96.

https://doi.org/10.1016/j.jcsr.2017.01.010

[3] L.-E. Lindgren, Computational Welding Mechanics - Thermomechanical and Microstructural Simulations, Woodhead Publishing in Materials, first ed., Cambridge England, 2007. https://doi.org/10.1201/9781439824092

[4] S. Kou, Welding Metallurgy, John Wiley \& Sons, Inc., second ed., Hoboken, New Jersey, 2003.

[5] J.A. Goldak, A. Chakravarti, M. Bibby, A new finite element model for welding heat sources, Metall. Trans. B 15 (1984) 299-305. https://doi.org/10.1007/BF02667333

[6] J.N. Dupont, A.R. Marder, Thermal efficiency of arc welding processes, Weld. J. 74 (1995) 406-416.

[7] B. Andersson, Thermal Stresses in a submerged-arc welded joint considering phase transformations, Trans. ASME 100 (1978) 356-362. https://doi.org/10.1115/1.3443504

[8] P. Knoedel, S. Gkatzogiannis, T. Ummenhofer, FE simulation of residual welding stresses: Aluminum and steel structural components, Key Engineering Materials 710 (2016) 268-274. https://doi.org/10.4028/www.scientific.net/KEM.710.268

[9] S. Gkatzogiannis, P. Knoedel, T. Ummenhofer, Influence of welding parameters on the welding residual stresses, Proceedings of the VII International Conference on Coupled Problems in Science and Engineering, Rhodes Island, Greece, June 12-14 (2017) 767-778.

[10] S. Gkatzogiannis, P. Knoedel, T. Ummenhofer, FE welding residual stress simulation Influence of boundary conditions and material models. EUROSTEEL 2017, September 13-15, 2017, Copenhagen, Denmark, (2017), Ernst \& Sohn Verlag für Architektur und technische Wissenschaften GmbH \& Co. KG, Berlin.

[11] W. Liu, J. Ma, F. Kong, S. Liu, R. Kovacevic, Numerical modeling and experimental verification of residual stress in autogenous laser welding of high-strength steel, Lasers Manuf. Mater. Process. 2 (2015) 24-42. https://doi.org/10.1007/s40516-015-0005-4

[12] C.H. Lee, K.H. Chang, Prediction of residual stresses in high strength carbon steel pipe weld considering solid-state phase transformation effects, Computers and Structures 89 (2011) 256-265. https://doi.org/10.1016/j.compstruc.2010.10.005

[13] ANSYS® Academic Research, Release 18.2, Help System, ANSYS, Inc., (2018).

[14] S. Gkatzogiannis, Finite Element Simulation of High Frequency Hammer Peening, Ph.D. thesis (in progress), KIT, Karlsruhe Institute of Technology, Department of Civil, Geo and Environmental Sciences, KIT Steel \& Lightweight Structures, 2018. 